\title{
Respiratory health in chrysotile asbestos miners in British Columbia: a longitudinal study
}

\author{
D A ENARSON, VALERIE EMBREE, LONIA MACLEAN, S GRZYBOWSKI \\ From the Respiratory Division, Vancouver General Hospital, University of British Columbia, Vancouver, BC \\ V5Z $3 J 5$ Canada
}

ABSTRACT A respiratory survey was undertaken in chrysotile asbestos miners in British Columbia consisting of a questionnaire, spirometry, chest radiography, and physical examination. The tests were performed in 1977 and again in 1983. The population groups studied included 63 "exposed" (working in the plant more than nine years), 52 "controls" (working in the plant less than five years), and 38 residents of the village at the minesite. A subset of 39 was identified with high exposure (worked in the mill more than five years). Measured levels of environmental particulates were similar over the entire period of operation of the plant ( 1.4 to 14.0 million particles per cubic foot and 0.788.0 fibres/cc in the mill; 0.2 to $2.7 \mathrm{mpcf}$ and 0.6 to $9.3 \mathrm{f} / \mathrm{cc}$ in the mine). The exposed groups were more likely to report cough and breathlessness than the two other groups and were also more likely to have abnormal FVC and chest $x$ ray films (the latter not significant, $p>0.05$ ) and to be more likely to have a combination of these abnormalities. There was no trend to progression in the combination of abnormalities associated with exposure on follow up. The heavily exposed group showed a significantly worse trend in FVC. This adverse trend was confined to those with initial abnormalities. Tobacco smoking did not increase the trend to progression in this group.

The respiratory health effects of asbestos exposure have been shown to be related to the dose of exposure, the type of work in which the exposure occurred, and the fibre type to which the individuals were exposed..$^{1-3}$ In many settings in which asbestos products are used the fibre type is mixed. In primary production in mines and mills, although the mined fibre predominates, others may also be present. Thus, for example, in some chrysotile mines tremolite asbestos is found. ${ }^{4}$ One can usually only refer to predominant fibre types in health studies of these working populations. Canada is a major producer of chrysotile asbestos, this material being mined most commonly in Quebec. British Columbia supplies a small amount of asbestos from its chrysotile mine in the northern part of the province which was opened in the early 1950s. Mineral analysis shows pure chrysotile asbestos with no amphibole content.

In 1977 we were asked to undertake a respiratory health survey among the workers at this time. We reexamined this population in 1983 . The following is a report of the study.

Accepted 22 June 1987

\section{Material and methods}

\section{STUDY GROUPS}

At the outset of the study three groups were selected. The first, the "exposed" group, included all employees who had worked at the mine for nine or more years. This group was further subdivided into two groups: one group (exposed, mill) had worked in the mill for five or more years and another group (exposed, other) consisted of all others, mostly in the open pit mine area. The second group, the "controls," included individuals of similar age whose employment at the mine was less than five years. The third group, the "residents," included all long term residents of the village. The control group could no longer be considered unexposed at follow up examination and must be viewed as an intermediate group.

\section{METHODS}

Questionnaire-A standardised questionnaire administered by trained interviewers included a medical section, a section on smoking habits, and a section on occupational history. ${ }^{5}$ Symptoms derived from this questionnaire included cough most days for 
as much as three months a year (cough), phlegm most days for as much as three months a year (phlegm), wheezing even without a cold (wheezing), breathlessness on hurrying on the level or walking up a slight hill (breathlessness). Non-smokers were defined as those who had had no exposure to tobacco for their entire life, current smokers were those with any regular consumption of tobacco within the past month, and ex-smokers as all others.

Limited physical examination-Examination was performed on site to determine the presence of pulmonary crackles.

Spirometry-Spirometry was performed at the worksite using a 13.5 l Collins spirometer. Each subject performed a minimum of five technically satisfactory forced expiratory manoeuvres, and the best forced expiratory volume in one second $\left(\mathrm{FEV}_{1}\right)$ and forced vital capacity (FVC) were used for analysis. Forced expiratory flow during the middle half of the FVC $\left(\mathrm{FEF}_{25-75 \%}\right)$ was obtained from the spirogram with the highest sum of FEV, and FVC. Predicted normal values were obtained from the data of Morris et al. ${ }^{6}$ As the average values of spirometry in controls were greater than $100 \%$ (the healthy worker effect), abnormal values for $\mathrm{FVC}$ and $\mathrm{FEV}_{\text {, were defined at }}$ less than $90 \%$ and for $\mathrm{FEF}_{25-75 \%}, 70 \%$.

Chest $x$ ray examination-All subects underwent a large posteroanterior $x$ ray examination of the chest. The films were read by two independent readers, one of whom is a $\mathbf{B}$ reader.

Asbestos associated abnormalities-These were defined as breathlessness, crackles, abnormal $x$ ray films, and abnormal FVC. ${ }^{\text {? }}$

\section{Statistical analysis}

When two items were being compared, cross tabulation was performed from which rates and proportions were calculated. For comparing the relation between two categorical variables, the chi-squared test was used. Where more than two variables were included in the analysis and the outcome was categorical, logistic regression analysis was used. For repeated measures on the same individual, the Maxwell-Stuart modification of the chi-squared test was used. ${ }^{8}$ For variables that were continuous and when two variables were being compared, analysis of variance was used. Statistical significance was accepted at the $5 \%$ level for each of the tests $(p<0.05)$.

\section{Results}

The measurements of airborne particulates were undertaken by the company on five occasions between 1954 and 1977 and we have received the results. Measurements before 1975 are reported in million
Table 1 Characteristics of the study groups

\begin{tabular}{|c|c|c|c|c|}
\hline & \multirow[b]{2}{*}{ Controls } & \multirow[b]{2}{*}{ Residents } & \multicolumn{2}{|l|}{ Exposed } \\
\hline & & & Mill & Other \\
\hline $\begin{array}{l}\text { No } \\
\text { Age (y) }\end{array}$ & $\begin{array}{l}52 \\
43 \pm 10\end{array}$ & $\begin{array}{l}38 \\
32\end{array}$ & $\begin{array}{l}24 \\
47\end{array}$ & $\begin{array}{l}39 \\
45 \pm 11\end{array}$ \\
\hline $\begin{array}{l}\text { Smoking: } \\
\text { Ever } \\
\text { Now } \\
\text { Years in area } \\
\text { Years in mine/mill }\end{array}$ & $\begin{array}{r}39(75) \\
27(52) \\
3 \pm 2 \\
1 \pm 2\end{array}$ & $\begin{array}{r}20(53) \\
16(42) \\
14 \pm 6 \\
1 \pm 1\end{array}$ & $\begin{array}{l}20(83) \\
14(58) \\
16 \pm 5 \\
14 \pm 6\end{array}$ & $\begin{array}{r}31(79) \\
18(46) \\
15 \pm 6 \\
6 \pm 7\end{array}$ \\
\hline
\end{tabular}

Values are mean \pm sd (per cent in parentheses).

particles per cubic foot, eight hour time weighted average. Mean values in various sites within the mill were unchanged over this period, varying from 1.4 to 14.0. Mean values at the minesite were considerably lower, varying from $0 \cdot 2$ to $2 \cdot 7$. After 1975 measurements were made using a membrane filter and expressed in fibres/cc, eight hour time weighted average. Again, no temporal trend was evident in the measurements which varied from 0.7 to 88.0 in the mill and 0.6 to 9.3 at the mine.

Residents of the village reported widespread asbestos dust around the town in the first two decades (the roads were spread with asbestos tailings) but no measurements are available. Measurements in 1976 and 1977 varied from 0.006 to $0.045 \mathrm{f} / \mathrm{cc}$.

A total of 153 individuals was examined in 1977: 52 controls, 38 residents, 24 exposed (other), and 39 exposed (mill). The controls and exposed groups did not differ in relation to age or smoking habit. The town residents, on the other hand, were younger and less likely to be cigarette smokers. Residents and exposed groups had lived in the village for an average of about 15 years whereas controls had lived in the town only 2.5 years on average. Those in the exposed (mill) group had the longest seniority at the workplace averaging about 14 years, the exposed (other) group averaged about six years, whereas residents averaged less than a year and controls just over one year (table 1).

Table 2 shows the prevalence of respiratory symptoms in the various groups in the 1977 survey. The prevalence among controls and residents did not differ for any of the symptoms. Each symptom was

Table 2 Prevalence of reported respiratory symptoms (No/\%) according to study group

\begin{tabular}{lrlll}
\hline & & \multicolumn{3}{c}{ Exposed } \\
\cline { 3 - 5 } & Controls & Residents & Mill & Other \\
\hline Cough & $13(25)$ & $6(16)$ & $10(42)$ & $14(36)^{*}$ \\
Phlegm & $8(16)$ & $7(18)$ & $9(38)$ & $13(33)$ \\
Wheeze & $11(22)$ & $6(16)$ & $10(42)$ & $12(31)$ \\
Breathlessness & $6(12)$ & $9(24)$ & $11(46)^{*}$ & $10(26)^{*}$ \\
\hline
\end{tabular}

* $p<0.05$ from chi-squared. 
Table 3 Mean values ( $\pm S D$ ) of spirometry by study group

\begin{tabular}{lllrl}
\hline & & \multicolumn{3}{c}{ Exposed } \\
\cline { 3 - 5 } & Controls & Residents & Mill & \multicolumn{1}{l}{ Other } \\
\hline FVC & $102 \pm 12$ & $101 \pm 14$ & $92 \pm 18$ & $100 \pm 15$ \\
FEV $_{1}$ & $105 \pm 13$ & $108 \pm 15$ & $96 \pm 18$ & $108 \pm 18$ \\
FEF $_{25} 75 \%$ & $108 \pm 30$ & $101 \pm 31$ & $101 \pm 32$ & $121 \pm 38$ \\
\hline Values are per cent of predicted normal. & &
\end{tabular}

Values are per cent of predicted normal.

more commonly reported in the exposed groups, statistically significant for cough in the exposed (other) group and for breathlessness in both exposed groups as compared with the control group $(\mathrm{p}<0.05$ from logistic regression analysis adjusting for age and smoking). The lowest mean levels of FEV and FVC occurred in the exposed (mill) group, although differences in mean levels among the groups were not statistically significant (table 3). Multiple logistic regression analysis was undertaken to determine the likelihood of having a low value of spirometry as compared with the control group. In this analysis the exposed (mill) group was significantly $(p<0.05)$ more likely to have a low $\mathrm{FEV}_{1}$ and $\mathrm{FVC}$ with odds ratios of 5.7 and 5.3 respectively compared with 1.2 and 2.0 for exposed (other) and 3.6 and 3.0 for town residents (neither significant), corrected for age, height, and smoking habit.

Of the $x$ ray abnormalities in the exposed groups, the highest profusion value was $1 / 1$. The total number of $x$ ray films with parenchymal abnormalities considered definitely present was six $(11 \%)$; one $(2 \%)$ showed pleural abnormality.

Table 4 shows the prevalence of asbestos associated abnormalities in the different groups. The highest prevalence for each of the asbestos associated abnormalities was observed among the exposed groups. Indeed, pulmonary crackles occurred only in exposed individuals. The increased prevalence, as compared with controls, was statistically significant for breathlessness and low FVC. Table 5 shows the frequency of the combination of abnormalities associated with exposure to asbestos. There are greater

Table 4 Distribution of various asbestos related abnormalities according to study group

\begin{tabular}{lllll}
\hline & & \multicolumn{3}{c}{ Exposed } \\
\cline { 4 - 5 } & Controls & Residents & Mill & Other \\
\hline Breathlessness & $6(12)$ & $9(24)$ & $11(46)^{*}$ & $10(26)^{*}$ \\
FVC $<90 \%$ & $7(14)$ & $7(18)$ & $11(46 \%)$ & $7(18)$ \\
Rales & $0-$ & $0-$ & $0-$ & $0-$ \\
Abnormal & $3(6)$ & $0-$ & $6(30)$ & $11(33)$ \\
$\quad x$ ray films & $3(6)$ & &
\end{tabular}

*p $<0.05 v$ controls from logistic regression analysis corrected for age and smoking habit (per cent in parentheses).
Table 5 Combinations of asbestos related abnormalities according to study group

\begin{tabular}{lcclc}
\hline & & \multicolumn{3}{c}{ Exposed } \\
\cline { 3 - 5 } & Controls & Residents & Mill & Other \\
\hline 0 & $35(70)$ & $22(67)$ & $6(30)$ & $12(36)$ \\
1 & $13(26)$ & $9(27)$ & $6(30)$ & $18(52)$ \\
2 & $2(4)$ & $2(6)$ & $6(30)$ & $3(9)$ \\
3 & $0-$ & $0-$ & $2(10)$ & $1(3)$ \\
\hline
\end{tabular}

$\mathrm{p}<0.01$ from chi-squared (combination of two or more have been combined) (per cent in parentheses).

numbers of abnormalities in both of the exposed groups as compared with residents and controls; the exposed groups are significantly more likely to have two or more abnormalities ( $p<0.05$ by chi-squared).

At the time of follow up examinations in 1983, many individuals were no longer in the area: $77 \%$ of controls, $45 \%$ of residents, and $46 \%$ of exposed groups. To determine whether they might have left the area because of illness related to exposure to asbestos, we looked at the distribution of asbestos related abnormalities at initial examination in relation to whether the individuals in the groups had left or stayed in the area. The differences between those who left and those who stayed were not statistically significant. We attempted to determine whether combinations of these abnormalities were likely to be associated with those who had left the area. Although individuals with asbestos associated abnormalities were more likely to leave the area compared with those who had no asbestos associated abnormalities, the difference was not statistically significant (table 6).

Comparison of trends in FVC in those examined in 1977 and 1983 by analysis of variance showed that the trend in the exposed (mill) group differed significantly from all other groups $(-62 \pm 41 \mathrm{ml} / \mathrm{y})$ that did not differ from each other $(+23 \pm 14 \mathrm{ml} / \mathrm{y})$. The comparison of trend according to smoking habit showed no statistically significant differences between those with different smoking habits. The trend in FVC varied significantly according to the presence of asbestos related abnormalities at initial examination. For those with no asbestos related signs in 1977, the

Table 6 Numbers (\%) of original participants who left before follow up examination, according to study group and presence of asbestosis signs

\begin{tabular}{lllll}
\hline & & \multicolumn{3}{c}{ Exposed } \\
\cline { 4 - 5 } & Controls & Residents & Mill & Other \\
\hline 0 & $26(74)$ & $7(32)$ & $2(33)$ & $3(25)$ \\
1 & $11(85)$ & $7(78)$ & $3(50)$ & $7(39)$ \\
2 & $1(50)$ & $0-$ & $4(67)$ & $2(67)$ \\
3 & $0-$ & $0-$ & $1(50)$ & $1(100)$ \\
\hline
\end{tabular}


mean annual trend in FVC was $68 \pm 80$; for those with one, the mean trend in FVC was $-22 \pm 102$; for those with two or more, the mean trend was $-148 \pm 102$.

Abnormal chest $x$ ray films and pulmonary crackles in 1977 were observed only in the exposed groups so it was not possible to determine differences among the groups in FVC trend associated with these abnormalities. For those in 1977 with breathlessness or abnormal FVC, the trend in FVC between 1977 and 1983 was significantly more negative in exposed groups compared with residents and controls. The effect of cigarette smoking on trend in FVC did not differ among the groups with and without asbestos related abnormalities.

The two exposed groups were statistically significantly more likely to show the appearance of new $x$ ray changes as compared with residents or controls ( $p<0.05$ by chi-squared). We were unable to show a relation between the presence of asbestos related signs in 1977 and the appearance of new $x$ ray changes in the groups.

For the new appearance (in 1983) of breathlessness, we were unable to show a difference among the various exposure groups. There were no other significant predictors identified. None of the individuals on follow up examination was observed to have the new appearance of pulmonary crackles.

We attempted to determine whether the number of asbestos associated abnormalities was greater at follow up examination than at the first examination. For this analysis, the Stuart Maxwell chi-squared test was used. The occurrence of initial and subsequent asbestos associated abnormalities were cross tabulated and the rates (per cent) of regression and progression of the signs of asbestosis were calculated. For control and resident groups, the rate of regression exceeded the rate of progression $(24 \% v 7 \%)$. For the two exposed groups, on the other hand, the rate of progression and of regression were similar $(30 \% v$ $26 \%$ ). The differences between the rates of progression and regression were not statistically significant in any of the groups.

\section{Discussion}

The most detailed studies of the respiratory health of chrysotile production workers have been reported since 1966 and come from Cyprus, ${ }^{9}$ Italy, ${ }^{10}$ and Quebec. ${ }^{112}$ Other reports have originated from the Soviet Union and Africa. These studies have documented significant decreases in the environmental concentrations of asbestos fibres over the past 30 years.

Comparable radiographic assessments of chrysotile production workers are available from Cyprus and
Quebec and showed a prevalence of irregular small opacities recognised as definitely present that was $10 \%$ for the former and $5 \%$ and $8 \%$ for the two latter sites. Pleural thickening was noted in $3-8 \%$ with a higher value seen in Cyprus. Chest $x$ ray abnormalities were much more common in studies from Italy $(29 \%$ and $13 \%)$.

Studies of lung function have been reported from Quebec and from Italy and in both cases levels of lung function were noted to be related to the abnormalities observed on the chest $x$ ray film. The Quebec studies showed that both chronic cough and breathlessness on exercise were increased with increasing asbestos exposure, and although cough was also affected by tobacco smoking, breathlessness was not.

There has been only one report of longitudinal assessment of the health of chrysotile miners with combined physiological and radiological parameters. ${ }^{13}$ In this study $75 \%$ of an original 1000 workers were studied six years later using questionnaire, spirometry, and chest $x$ ray examination. It was noted that regression in reported breathlessness was equally as likely as progression on follow up. On the other hand, the prevalence of abnormal forced vital capacity was noted to increase (4-15\%) and the chest $x$ ray film was noted to progress to more severe changes $(25-30 \%)$. The authors stated that, after adjustment for age and smoking habit, only the increase in breathlessness was significantly associated with the index of exposure used in the study.

Levels of asbestos exposure measured over a comparable period with those in Italy, Cyprus, and Quebec are lower in British Columbia, being similar to levels observed in the 1970s in the other sites. Unlike the other sites, there was no clear trend toward reduction in exposure levels up to 1975.

We have confirmed an increased prevalence of cough and breathlessness in the exposed groups, as in the Quebec studies. The decreased level of forced vital capacity was restricted to those working in the mill area, an area known for its high levels of exposure to asbestos fibres. The degree of FVC deficit in mill workers was of a similar magnitude to that reported in Quebec $(8-9 \%)$. The prevalence of chest $x$ ray abnormalities, especially pleural changes, was lower in this study compared with previously reported studies. This is particularly surprising in that the selection for this study included a prolonged period of exposure. On the other hand, measured levels of exposure were lower in the present study as compared with the other studies. In addition, the mineral in Quebec contains an amphibole component ${ }^{4}$ not present in British Columbia.

The study was hampered to a large degree by the great mobility and high turnover rate at the worksite. Such a phenomenon has been characteristic of the site 
since it first opened with only a small minority remaining employed for more than five years. Undoubtedly the remote location has an influence; we were unable to show selection for work based on health.

The association of progression in asbestos related abnormalities with their initial presence may indicate a greater exposure in such individuals. On the other hand, individual susceptibility due to host factors may explain the observation. We have been unable to differentiate between these possibilities. It is of interest to note that current smokers were not more likely to experience an adverse outcome in $\mathrm{FEV}_{1}$, suggesting an increased relative effect of asbestos exposure in non-smokers. Progression in asbestos related abnormalities was isolated to those who showed the signs at first examination. This would imply that, after nine years of exposure, those who were going to show an adverse trend already had some indication of it: they may represent the group with greatest exposure or the greatest susceptibility.

\section{References}

1 Irwig RS, Du Toit J, Sluis-Cremer GK, et al. Risk of asbestosis in crocidolite and amosite mines in South Africa. Ann NY Acad Sci 1979;330:34-52.

2 Rossiter CE, Bristol LJ, Cartier PH, et al. Radiographic changes in chrysotile asbestos mine and mill workers of Quebec. Arch Environ Health 1972:24:388-400.

3 Felton JS. Radiographic search for asbestos-related disease in a naval shipyard. Ann NY Acad Sci 1979:330:341-52.

4 Churg A. Lung asbestos content in long-term residents of a chrysotile mining town. Am Rev Respir Dis 1986;134:125-7.

5 American Lung Association. Recommended respiratory diseases questionnaire for use with adults and children in epidemiological research. Am Rev Respir Dis 1978;118:6-7.

6 Morris JF, Koski A. Johnson LC. Spirometer standards for healthy non-smoking adults. Am Rev Respir Dis 1971; 103:57-67.

7 Becklake MR. Asbestos related diseases of the lung and other organs. Their epidemiology and implications for clinical practice. Amer Rev Respir Dis 1976;114:187-227.

8 Fleiss JL. Statistical methods for rates and proportions. 2nd ed. New York: John Wiley 1981:119-23.

9 Constantinides in McDonald JC. Asbestosis in chrysotile mines and mills. In: Bogovskai P, Gilson JC, Timbrell V, Wagner JC, eds. Biological effects of ashestos. Lyon: International Agency for Research on Cancer, 1973:155-9. (IARC sci publ No 8.)

10 Vigliani in McDonald JC. Asbestosis in chrysotile mines and mills. In Bogovskai P, Gilson JC, Timbrell V, Wagner JC, eds. Biological effects of asbestos. Lyon: International Agency for Research on Cancer. 1973:155-9. (IARC sci publ No 8.)

11 McDonald JC, Becklake MR, Gibbs GW, McDonald AD, Rossiter CE. The health of chrysotile asbestos mine and mill workers of Quebec. Arch Environ Health 1974;28:61-8.

12 Becklake MR, Fournier-Massey G, Rossiter CE. McDonald JC. Lung function in chrysotile asbestos mine and mill workers of Quebec. Arch Environ Health 1972;24:401-9.

13 Becklake MR. Thomas D, Liddell FDC, McDonald JC. Followup respiratory measurements in Quebec chrysotile asbestos miners and millers. Scand J Work Environ Health 1982;8: 105-10.

\section{Destruction of manuscripts}

From 1 July 1985 articles submitted for publication will not be returned. Authors whose papers are rejected will be advised of the decision and the manuscripts will be kept under security for three months to deal with any inquiries and then destroyed. 